JPE 11-5-5

\title{
Analysis of an LCLC Resonant Converter with a Capacitive Output Filter
}

\author{
Mehrdad Jafarboland ${ }^{\dagger}$ \\ $\dagger$ Dept. of Electrical Engineering, Malek- Ashtar University of Technology, Isfahan, Iran
}

\begin{abstract}
This paper presents an analysis of a 4th order LCLC resonant converter with a capacitive output filter using the state-space approach. The analysis of the converter shows that there are four intervals in a half period. In each interval, the state-space equations are obtained. Due to the soft switching of the converter, an exact equation for the Zero Voltage Switching (ZVS) time and the maximum dead time of the inverter switches are presented. The simulation and experimental results obtained from a $10 \mathrm{kv}$, $370 \mathrm{w}$ prototype confirm the validity of the theoretical analysis.
\end{abstract}

Key Words: Fourth order LCLC resonant converter, State -space approach, ZVS time

\begin{tabular}{ll} 
& \multicolumn{1}{c}{ NOMENCLATURE } \\
$C_{p}$ & Parallel resonant capacitance $(\mathrm{F})$ \\
$C_{s}$ & Series resonant capacitance $(\mathrm{F})$ \\
$C_{f}^{\prime}$ & Output filter capacitance $(\mathrm{F})$ \\
$L_{p}$ & Parallel resonant inductance $(\mathrm{H})$ \\
$L_{s}$ & Series resonant inductance $(\mathrm{H})$ \\
$n$ & Transformer turns ratio $(\mathrm{Nsec} / \mathrm{Npri})$ \\
$R_{L}^{\prime}$ & Load resistance $(\Omega)$ \\
$V_{\text {out }}^{\prime}$ & DC output voltage $(\mathrm{V})$ \\
$i_{L_{p}}$ & Current of the parallel resonant inductance $(\mathrm{A})$ \\
$i_{L_{s}}$ & Current of the series resonant inductance $(\mathrm{A})$ \\
$v_{C_{p}}$ & Parallel resonant capacitor voltage $(\mathrm{V})$ \\
$v_{C_{s}}$ & Series resonant capacitor voltage $(\mathrm{V})$ \\
$t_{Z V S}$ & Time between the output voltage of the inverter \\
& and the input current waveforms of the resonant \\
& circuit
\end{tabular}

\section{INTRODUCTION}

These days, soft switching resonant converters are widely used in applications where high efficiency, high power density, and reduced EMI are of great importance [1]-[12]. There are many resonant topologies introduced in the literature [3]. Resonant converters with three or more resonant components present better performance and better dynamic response. In addition, by using a higher order resonant circuit, it is possible to absorb all of the parasitic components of a converter, especially at very high switching frequencies [3], [12]. The LCLC resonant inverter is a forth order resonant topology which has been successfully used in different industrial applications such as space power distribution systems, resonant inverters, Ion

\footnotetext{
Manuscript received Jan. 1, 2011; revised Jul. 19, 2011

Recommended for publication by Associate Editor Yong-Chae Jung.

$\dagger$ Corresponding Author: jmehrdad@mut-es.ic.ir

Tel: +98-312-52-25042, Fax: +98-312-52-25139, Malek-ashtar Univ.

Dept. of Electrical Engineering, Malek-ashtar University, Iran
}

generator power supplies, multi lamp operation ballasts, renewable energy power conditioning systems, constant-current power supplies and dual-output resonant converters [13]-[19]. This topology employs more parasitic elements and has many desirable characteristics. Therefore, it seems to be a good candidate for high voltage conversion [20]-[25]. The converter of this topology uses an inductive output filter similar to a Parallel Resonant Converter (PRC) [1], [2]. In [12], [26] LCLC resonant converters with an LC output filter are analyzed using the First Harmonic Approximation technique (FHA). In high voltage applications, a resonant converter with a capacitive output filter is used, because the inductor in an output filter is bulky and very difficult to fabricate [20]-[25]. Fig. 1 shows a schematic of an LCLC resonant converter with a capacitive output filter. The absence of an inductor at the output filter causes the input voltage of the transformer to be clamped at the output voltage level that is divided in the transformer turns ratio, $\mathrm{n}$ while the power is transferred from the resonant circuit to the output which results in a phase shift between the transformer voltage and current [6]-[8]. Once the output rectifier current reaches zero, the output rectifier diodes turn off and the energy is fed into the resonant circuit. Consequently, in the FHA technique, the equivalent resistor cannot describe the behavior of the load side of the converter. Analysis of this converter is very complex, because there are different intervals of operation. The purpose of this paper is to analyze the different modes of this converter by the state-space approach. Due to the advantages of operation above resonance (lagging mode) [1], an exact equation is obtained for the time required to operate in this mode.

In section II, by using the state-space approach, the operating modes and a circuit description of an LCLC resonant converter with a capacitive output filter is presented. In section III, the state-space equations is solved by using the initial 


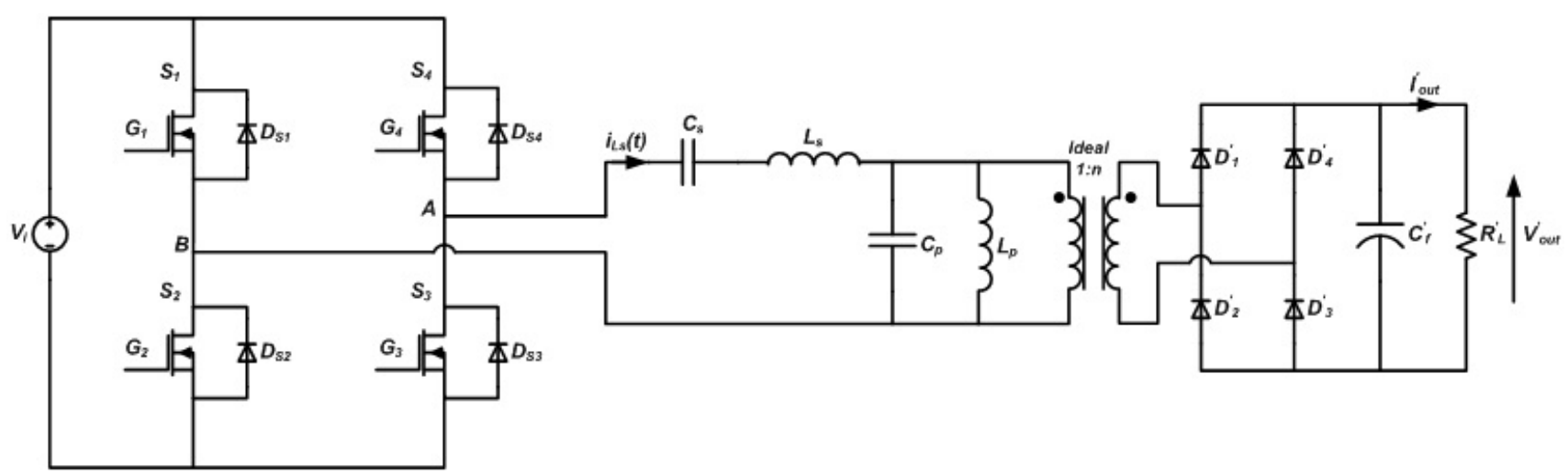

Fig. 1. Schematic of LCLC resonant converter with capacitive output filter.

conditions of the state variables and an exact equation obtained for the ZVS region. A performance analysis of the resonant converter is shown in section IV using Orcad simulation and experimental results.

\section{Operating Modes AND Circuit Description}

Studying the converter shows that there are eight modes in one switching period. Due to the similarities between the waveforms and the equivalent circuit in the second half of a switching period, the equivalent circuit of the converter is analyzed for half a period. The main theoretical waveforms of the converter and the equivalent circuit for each interval are shown in Fig. 2 and Fig. 3, respectively. Also, the status of the converter switches and diodes is presented in Table I. The following assumption is used in the analysis of this converter:

All the switches, diodes and other passive components in Fig. 1 are ideal.

The output filter capacitor is large enough to assume that the output voltage is constant..

In all of the equations, all the variables are transferred to the primary side of the transformer.

Interval 1[t0-t1]: This interval starts by turning off $\mathrm{S} 2$ and $\mathrm{S} 4$. Therefore the body diode of S1 and S3 is forced to conduct and the input voltage is placed across the resonant circuit. By choosing state-space variables for the capacitor voltage and the inductor current that are mentioned in (1), the state-space representation of the converter is given by:

$$
\begin{gathered}
X=\left[\begin{array}{llll}
i_{L_{s}} & v_{C_{s}} & i_{L_{p}} & v_{C_{p}}
\end{array}\right] \\
\frac{d}{d t}\left[\begin{array}{l}
i_{L_{s}} \\
v_{C_{s}} \\
i_{L_{p}} \\
v_{C_{p}}
\end{array}\right]=\left[\begin{array}{cccc}
0 & \frac{-1}{L_{s}} & 0 & \frac{1}{L_{s}} \\
\frac{1}{C_{s}} & 0 & 0 & 0 \\
0 & 0 & 0 \frac{-1}{L_{p}} & \\
\frac{-1}{C_{p}} & 0 \frac{1}{C_{p}} & 0
\end{array}\right] *\left[\begin{array}{l}
i_{L_{s}} \\
v_{C_{s}} \\
i_{L_{p}} \\
v_{C_{p}}
\end{array}\right] \\
+\left[\begin{array}{cc}
\frac{-1}{L_{s}} & 0 \\
0 & 0 \\
0 & 0 \\
0 & 0 \\
0 & 0
\end{array}\right] *\left[\begin{array}{c}
V_{i} \\
V_{o}
\end{array}\right] .
\end{gathered}
$$

At the end of this interval, the parallel capacitor voltage reaches to Vo.

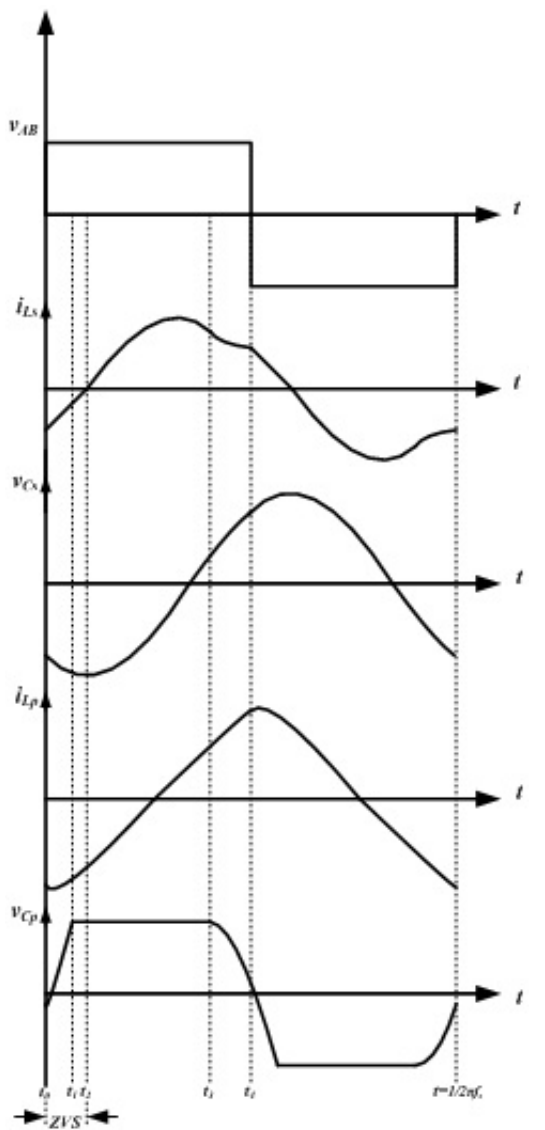

Fig. 2. Main theorical waveforms of the LCLC resonant converter with capacitive output filter.

Interval 2[t1-t2]: In this interval, the value of the parallel capacitor voltage is $\mathrm{V}_{o}$ and the output rectifier diodes is on. The clamping of the parallel capacitor voltage causes a decrease in the order of the state-space equations, thus the parallel inductance current increases linearly and the difference between the series and parallel inductance current is transferred to the output of the converter via a high voltage transformer.

The order of the state-space equations for this interval is two and as follows:

$$
\frac{d}{d t}\left[\begin{array}{l}
i_{L_{s}} \\
v_{C_{S}}
\end{array}\right]=\left[\begin{array}{cc}
0 & \frac{-1}{L_{s}} \\
\frac{1}{C_{s}} & 0
\end{array}\right] *\left[\begin{array}{c}
i_{L_{s}} \\
v_{C_{S}}
\end{array}\right]+\left[\begin{array}{cc}
\frac{-1}{L_{s}} & \frac{1}{L_{s}} \\
0 & 0
\end{array}\right] *\left[\begin{array}{c}
V_{i} \\
V_{o}
\end{array}\right] .
$$




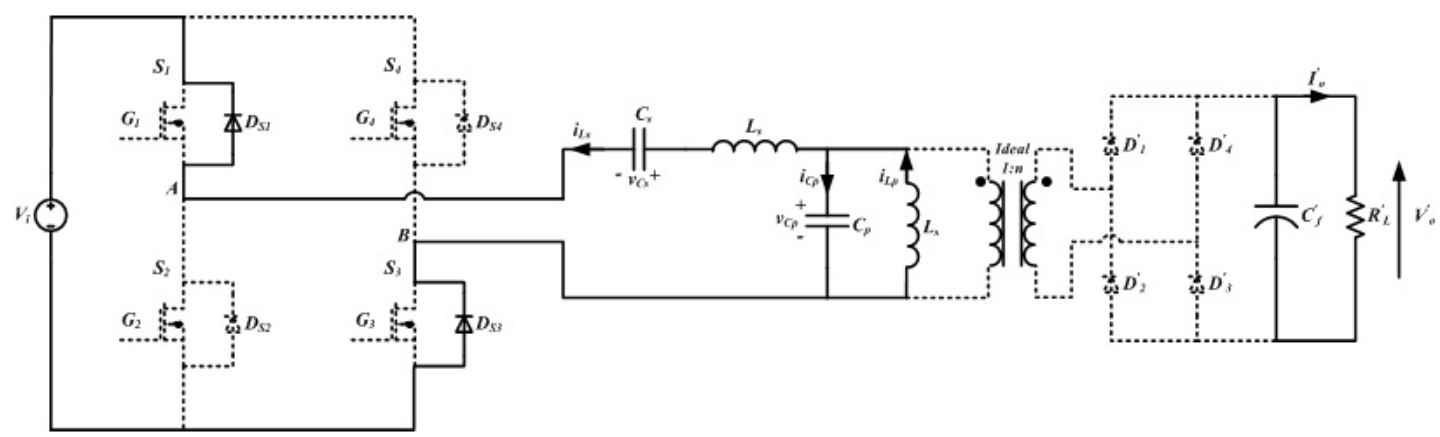

(a)

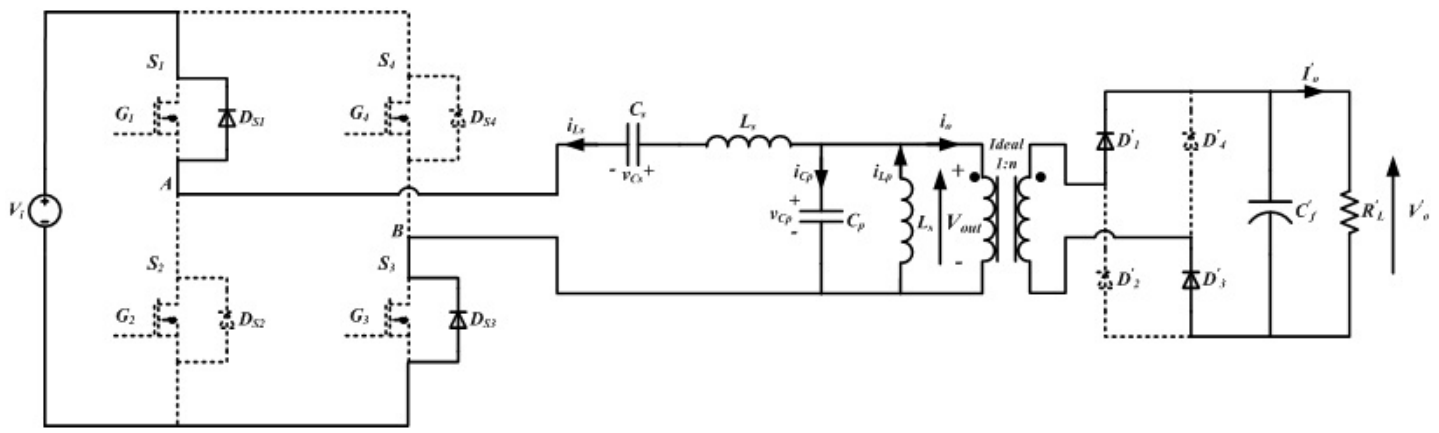

(b)

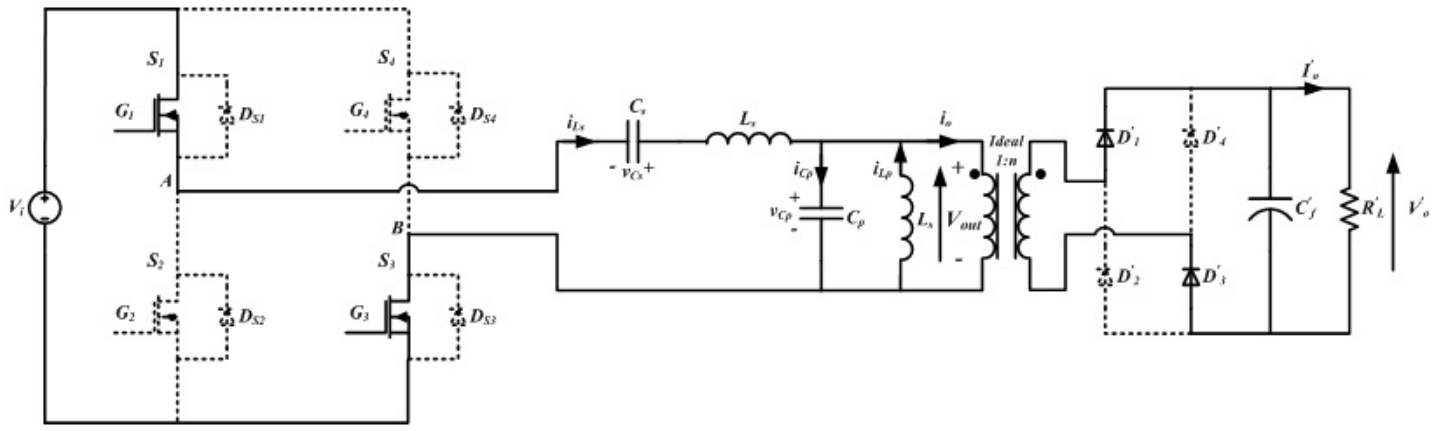

(c)

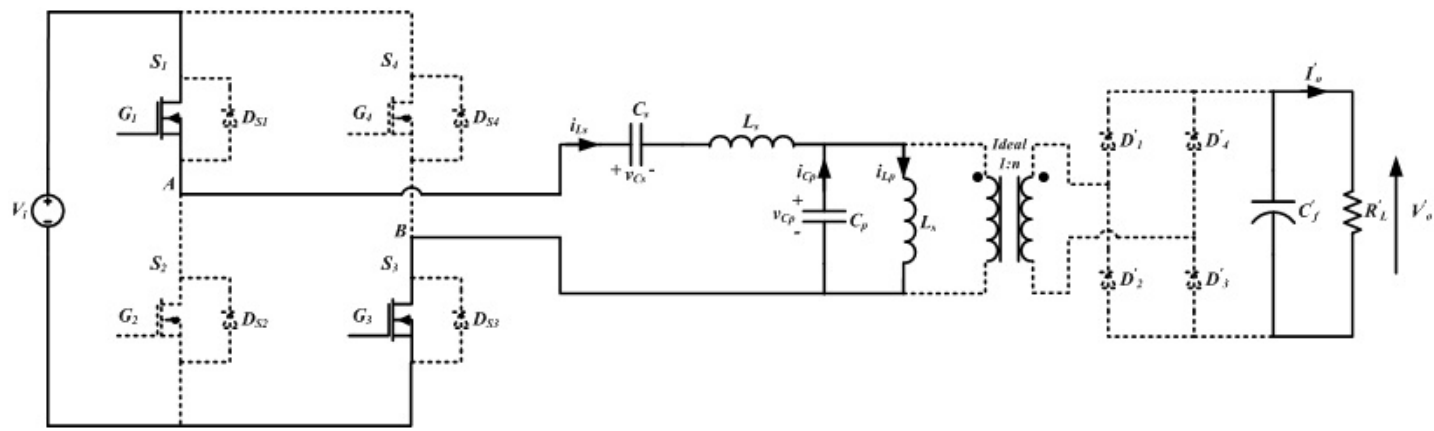

(d)

Fig. 3. Equivalent circuit for each operating interval at (a). [t0-t1] (b). [t1-t2] (c). [t2-t3] (d). [t3-t4].

TABLE I

SWITCHING CONDITION For THE SWITCHES AND Diodes IN DifFERENT INTERVALS

\begin{tabular}{|c|c|c|c|c|c|c|c|}
\hline Interval & $\boldsymbol{S}_{1}$ & $\boldsymbol{S}_{2}$ & $\boldsymbol{S}_{3}$ & $\boldsymbol{S}_{4}$ & $\boldsymbol{D}_{1} / \boldsymbol{D}_{3}$ & $\boldsymbol{D}_{2} / \boldsymbol{D}_{4}$ & Description \\
\hline I & $\mathrm{D}_{S 1}$ & & $\mathrm{D}_{S 3}$ & & & & \\
\hline II & $\mathrm{D}_{S 1}$ & & $\mathrm{D}_{S 3}$ & & Conduction & & Po. Trans. \\
\hline III & $\mathrm{T}_{S 1}$ & & $\mathrm{~T}_{S 3}$ & & Conduction & & Po. Trans. \\
\hline IV & $\mathrm{T}_{S 1}$ & & $\mathrm{~T}_{S 3}$ & & & & \\
\hline
\end{tabular}


It is necessary to mention that the end of this interval is the last time for the ZVS condition. As a result, S1 and S3 must be turned on via gate signals.

Interval 3[t2- $\mathrm{t} 3]$ : In this interval the sign of the series inductance current is positive and crosses through the transistor of S1 and S3. The power is already transferred to the output and in this mode the state-space equations is:

$$
\frac{d}{d t}\left[\begin{array}{l}
i_{L_{s}} \\
v_{C_{s}}
\end{array}\right]=\left[\begin{array}{cc}
0 & \frac{1}{L_{s}} \\
\overline{-1} & 0
\end{array}\right] *\left[\begin{array}{c}
i_{L_{s}} \\
v_{C_{s}}
\end{array}\right]+\left[\begin{array}{cc}
\frac{1}{L_{s}} & \frac{-1}{L_{s}} \\
0 & 0
\end{array}\right] *\left[\begin{array}{c}
V_{i} \\
V_{o}
\end{array}\right]
$$

The end of this interval occurs when the input current of the transformer reaches to zero and the output rectifier is turned off. Interval 4[t3-t4]: In this interval, the output rectifier is off and the parallel capacitor starts to discharge. As in the first interval, the order of the state-space equations is four and is given in (5)

$$
\begin{aligned}
\frac{d}{d t}\left[\begin{array}{l}
i_{L_{s}} \\
v_{C_{s}} \\
i_{L_{p}} \\
v_{C_{p}}
\end{array}\right] & =\left[\begin{array}{cccc}
0 & \frac{-1}{L_{s}} & 0 & \frac{-1}{L_{s}} \\
\frac{1}{C_{s}} & 0 & 0 & 0 \\
0 & 0 & 0 & \frac{1}{L_{p}} \\
\frac{1}{C_{p}} & 0 & \frac{-1}{C_{p}} & 0
\end{array}\right] *\left[\begin{array}{c}
i_{L_{s}} \\
v_{C_{s}} \\
i_{L_{p}} \\
v_{C_{p}}
\end{array}\right] \\
+ & {\left[\begin{array}{cc}
\frac{1}{L_{s}} & 0 \\
0 & 0 \\
0 & 0 \\
0 & 0 \\
0 & 0
\end{array}\right] *\left[\begin{array}{c}
V_{i} \\
V_{o}
\end{array}\right] . }
\end{aligned}
$$
off.

The end point of this interval is when S1 and S3 are turned

\section{Solving State-Space Equations}

The steady state analysis of the converter is obtained by using the state-space equations that are obtained for the four intervals and by matching the initial condition of each interval with the end values of the previous interval. It is necessary to bear in mind that the values of the state variables at the end of the fourth interval are equal to the initial conditions of the first interval but with the opposite sign. In interval 1 , the order of the resonant circuit is four and therefore there are four times the constant in this interval and the state variables change exponentially. Using the initial condition for this interval that is mentioned in (6), the answer of the series inductance current is given as follows:

$$
\begin{aligned}
& X_{t_{0}}=\left[\begin{array}{llll}
I_{L_{s 0}} & V_{C_{s 0}} & I_{L_{p 0}} & V_{C_{p 0}}
\end{array}\right] \\
& i_{L_{S}}(t)=C_{1} e^{-0.5 \alpha t}+C_{2} e^{0.5 \alpha t}+C_{3} e^{-0.5 \beta t}+C_{4} e^{0.5 \beta t}
\end{aligned}
$$

where the values of $\alpha$ and $\beta$ are given in (8) and (9), respectively (on the bottom of this page).

$$
\begin{aligned}
& \alpha= \\
& \frac{\sqrt{-2 C_{s} L_{s} C_{p} L_{p}\left(C_{p} L_{p}+C_{s} L_{s}+C_{s} L_{p}+\right.}}{\left.C_{p}^{2} L_{p}^{2}-2 C_{s} L_{s} C_{p} L_{p}+2 C_{p} C_{s} L_{p}^{2}+C_{s}^{2} L_{s}^{2}+2 C_{s}^{2} L_{s} L_{p}+C_{s}^{2} L_{p}^{2}\right)}
\end{aligned}
$$

$$
\begin{aligned}
& \beta= \\
& \frac{\sqrt{-2 C_{s} L_{s} C_{p} L_{p}\left(C_{p} L_{p}+C_{s} L_{s}+C_{s} L_{p}-\right.}}{\sqrt{\left.C_{p}^{2} L_{p}^{2}-2 C_{s} L_{s} C_{p} L_{p}+2 C_{p} C_{s} L_{p}^{2}+C_{s}^{2} L_{s}^{2}+2 C_{s}^{2} L_{s} L_{p}+C_{s}^{2} L_{p}^{2}\right)}} \\
& C_{s} L_{s} C_{p} L_{p}
\end{aligned}
$$

The answer of the other state variables are similar to (7) but with different constant coefficients. The terms of $\mathrm{V}_{i}$ and $\mathrm{V}_{o}$ can exist in $\mathrm{v}_{C s}$ and $\mathrm{v}_{C p}$. By using the initial conditions and placing them in the answers of the state variables, the coefficient constants are obtained as a function of the initial conditions and the converter parameters.

As previously mentioned, in interval 2 the order of the resonant circuit is two because of the parallel capacitor voltage clamping and the answers of the state variables are:

$$
\begin{gathered}
i_{L_{s}}(t)=C_{1} \sin \left(\omega_{0} t\right)+C_{2} \cos \left(\omega_{0} t\right) \\
v_{C_{S}}(t)=\frac{1}{Z_{0}}\left(C_{1} \cos \left(\omega_{0} t\right)-C_{2} \sin \left(\omega_{0} t\right)\right)+V_{o}-V_{i}
\end{gathered}
$$

where

$$
Z_{0}=\sqrt{\frac{L_{s}}{C_{s}}} \text { and } \omega_{0}=\frac{1}{\sqrt{L_{s} C_{s}}} .
$$

The parallel capacitor voltage is Vo and the parallel inductor current increases linearity.

$$
i_{L_{p}}(t)=C_{3}-\frac{V_{o}}{L_{p}} t .
$$

For operating the converter under the ZVS condition, before the end point of this interval, the transistor of the switches S1 and S3 must be turned on via gate signals. Therefore this point must be calculated ( $\mathrm{t} 2)$ and the dead time is selected so that the ZVS operation is obtained.

The third interval is similar to the second interval and the only difference is the sign of $\mathrm{i}_{L s}$.

$$
\begin{gathered}
i_{L_{s}}(t)=\frac{1}{Z_{0}}\left(C_{2} \cos \left(\omega_{0} t\right)-C_{1} \sin \left(\omega_{0} t\right)\right) \\
v_{C_{S}}(t)=i_{L_{s}}(t)=C_{2} \sin \left(\omega_{0} t\right)+C_{1} \cos \left(\omega_{0} t\right)-V_{i}+V_{o} .
\end{gathered}
$$

$\mathrm{Z} 0$ and $\omega 0$ are given in (12) and the answer of the parallel inductor current is similar to (13).

The equivalent circuit in interval 4 and the answer of the state variables are similar to interval 1. At the end of this interval the total time of the analysis and the values of the state variables are:

$$
\begin{aligned}
& t_{4}-t_{0}=\frac{T_{s}}{2} \\
& X_{t_{4}}=-X_{t_{0}}=\left[\begin{array}{llll}
-I_{L_{s 0}} & -V_{C_{s 0}} & -I_{L_{p 0}} & -V_{C_{p 0}}
\end{array}\right] .
\end{aligned}
$$

By using the answer of the state variables in different intervals and assuming (16) and (17), all of the coefficients and duration of each interval are obtained.

One of the most important times is $\mathrm{t} 2$, which defines the ZVS operation of the converter. If soft switching of the converter is desirable, this time must be positive in the steady state operation and the dead must not be longer than this time. By using the state-space operation and with the assumption 


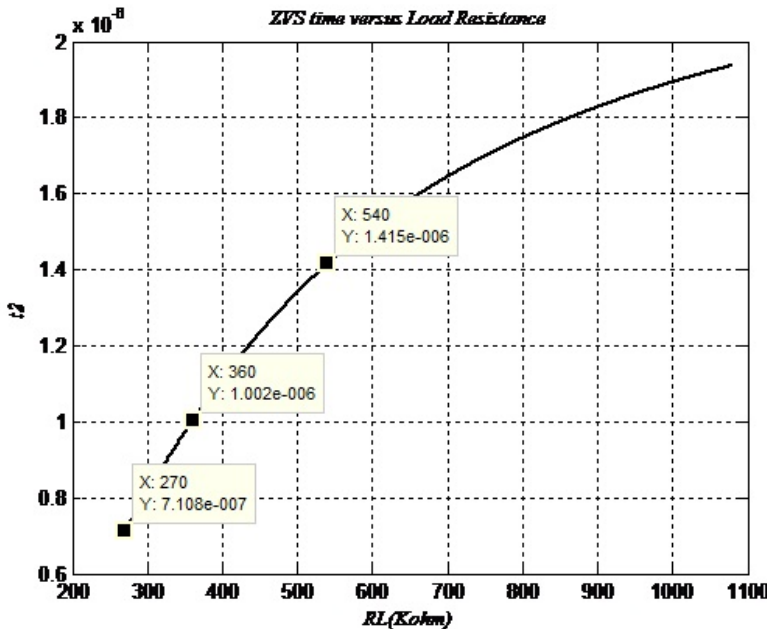

Fig. 4. ZVS time versus load resistance with the parameters of TABLE II.

TABLE II

Parameters of LCLC Resonant CONVERTER For Determining ZVS REGION

\begin{tabular}{|c|c|}
\hline Parameters & Value \\
\hline $\mathrm{P}_{o}$ & $370 \mathrm{~W}$ \\
\hline $\mathrm{V}_{\text {in }}$ & $110 \mathrm{~V}, 50 \mathrm{~Hz}$ \\
\hline $\mathrm{V}_{\text {out }}$ & $10 \mathrm{kV}$ \\
\hline Series Capacitor, $\mathrm{C}_{s}$ & $40 \mathrm{nF}$ \\
\hline Series Inductor, $\mathrm{L}_{s}$ & $63 \mathrm{uH}$ \\
\hline Parallel Capacitor, $\mathrm{C}_{p}$ & $10 \mathrm{nF}$ \\
\hline Parallel Inductor, $\mathrm{L}_{p}$ & $63 \mathrm{uH}$ \\
\hline Switching Frequency & $100 \mathrm{kHz}$ \\
\hline Transformer turns ratio, $\mathrm{n}$ & 67 \\
\hline Output Capacitor, $\mathrm{C}_{f}$ & $13 \mathrm{nF}$ \\
\hline
\end{tabular}

that the values of $\alpha$ and $\beta$ are negative, the state variables terms can be change to sinusoidal and cosinusoidal term and then $\mathrm{t} 2$ can be calculated by (18) (in Appendix).

For studying the ZVS condition and soft switching of the converter, $\mathrm{t} 2$ is plotted for specified parameters and presented in TABLE II and with a different load resistance. The result is shown in Fig. 4 and it specifies that for the full load condition, the ZVS time is about $710 \mathrm{nsec}$ and therefore the dead time between switches must be less than this time. It is necessary to mentioned that in the resonant converter the dead time cannot be determined by considering the switches specifications, because the resonant circuit current must discharge the intrinsic parallel capacitor of the switch before the transistor of the switch can be turned on [27].

\section{Performance Analysis, Simulation And EXPERIMENTAL RESULTS}

The performance of the LCLC resonant converter is analyzed through computer simulations and experimental results. The simulations are carried out in Orcad and the result for the full-load condition is illustrated in Fig.5 and TABLE III, respectively.

The resonant circuit state variables in each part of Fig. 5 are the same as the theoretical waveforms shown in Fig. 2. According to Fig. 5(a), the ZVS time in the Orcad simulation and one obtained from the analyzed equation are very close.

A $10 \mathrm{kV}, 370 \mathrm{~W}$ prototype converter based on the parameters mentioned in TABLE II is realized to verify the accuracy of

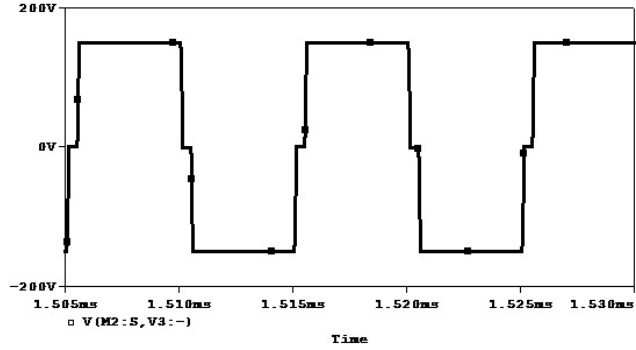

(a)

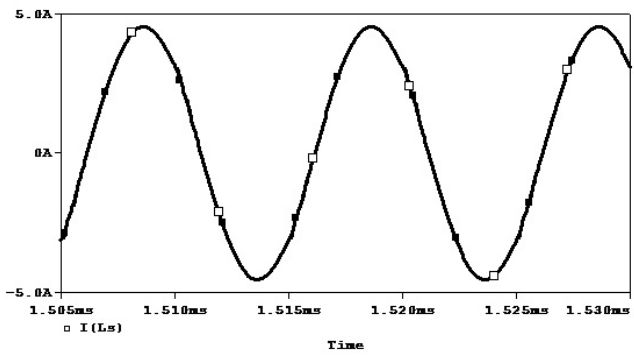

(b)

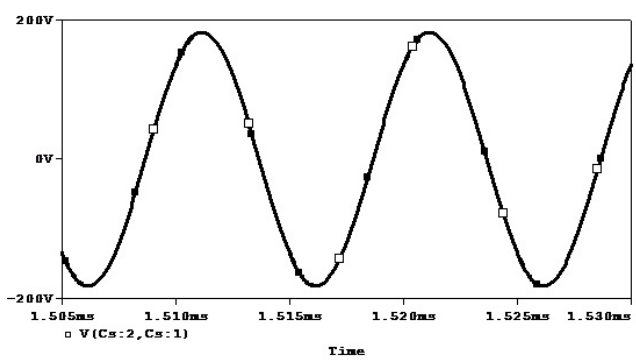

(c)

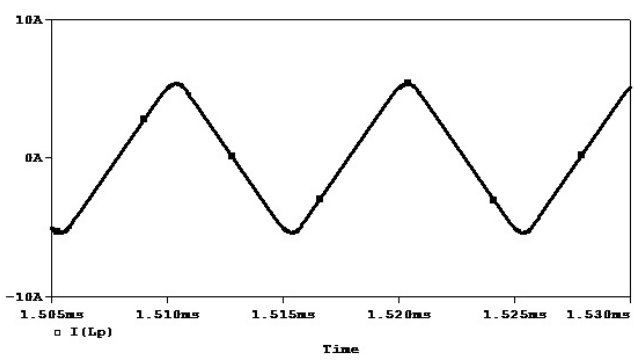

(d)

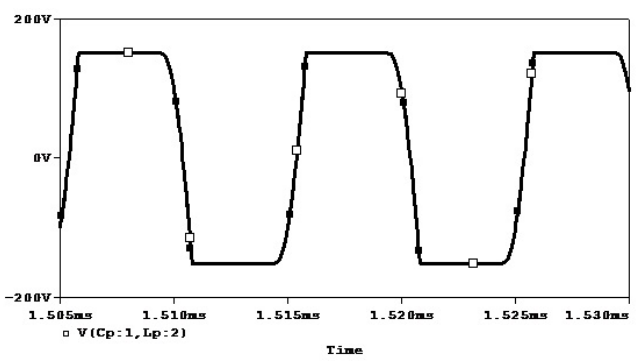

(e)

Fig. 5. Simulation results of the LCLC resonant converter with capacitive output filter for full resistance load. (a) Output voltage of the inverter. (b) Series inductor current. (c) Series capacitor voltage. (d) Parallel inductor current. (e) Parallel capacitor voltage. 


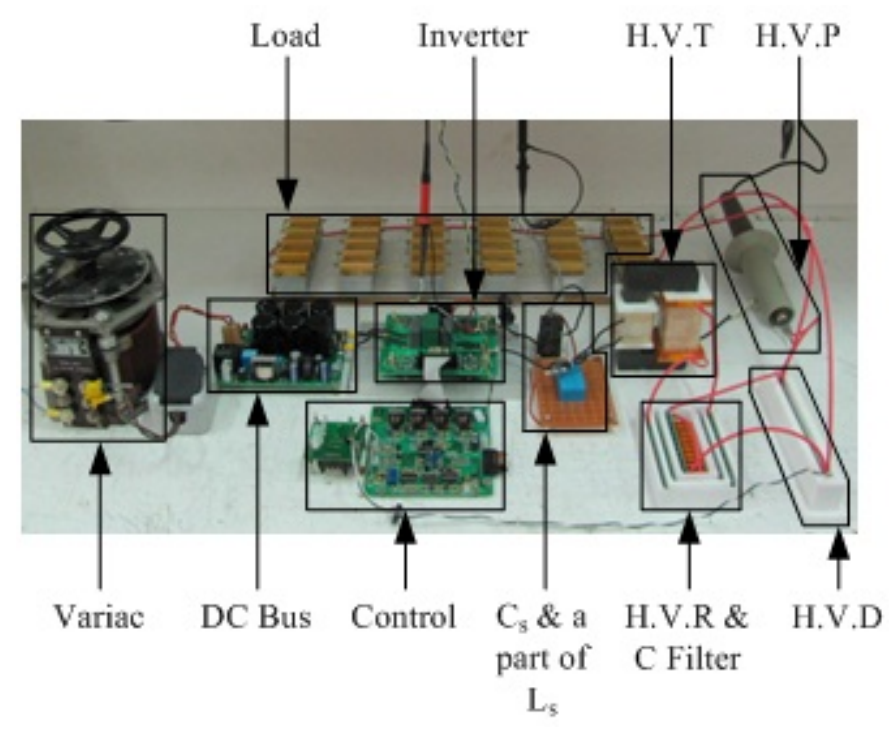

Fig. 6. Experimental prototype setup for a $10 \mathrm{kV}, 370 \mathrm{w}$ resonant converter.

TABLE III

Simulation RESUlts OF LCLC RESONANT CONVERTER WITH ORCAD

\begin{tabular}{|c|c|c|c|}
\hline$R_{L}^{\prime}$ & $t_{\text {ZVS }}$ & $i_{L_{s}, \text { peak }}$ & $V_{\text {out }}^{\prime}$ \\
\hline $270 \mathrm{~K} \Omega$ & $800 \mathrm{nsec}$ & $4.5 \mathrm{~A}$ & $10 \mathrm{kV}$ \\
\hline $360 \mathrm{~K} \Omega$ & $1.1 \mu \mathrm{sec}$ & $3.9 \mathrm{~A}$ & $10 \mathrm{kV}$ \\
\hline $540 \mathrm{~K} \Omega$ & $1.5 \mu \mathrm{sec}$ & $3.4 \mathrm{~A}$ & $10 \mathrm{kV}$ \\
\hline
\end{tabular}

the theoretical analysis and the performance of LCLC resonant converter. The whole parts of the realized resonant converter are shown in Fig. 6.

In this converter, the line voltage is rectified through a diode bridge rectifier and there is a capacitive filter to get the DC voltage. Because of the ripple of the rectified voltage, the filter capacitance value is selected such as the maximum ripple at full load is equal to $10^{\mathrm{V}}$. As a result, the input voltage of the converter is $150^{V D C}$. A full-bridge inverter based on MOSFETs is used to produce the high frequency square wave voltage. A FA57SA50LC and a pulse transformer are used as the full-bridge switches and the gate driver of the switches, respectively.

The series capacitor, Cs and an inductor, which is added in series with the transformer to absorb the leakage inductance to create the series resonant inductor, are the only discrete components since the other resonant components are integrated into the high frequency transformer [5]. Fig. 7 shows the experimental results of the LCLC resonant converter.

According to this figure, the ZVS time is equal to $800 \mathrm{nsec}$ and the full-bridge switches are turned on under zero voltage and the ZVS time value is very close to that predicted by the time domain analysis and the Oracd simulation of the converter. The matching problems that occur between the analytical, the simulation and the experimental results exist for the following reasons:

1) In the state-space analysis of the resonant converter, the power loss of the elements has not been considered.

2) The output capacitance of the MOSFET has been withdrawn in the analytical model, but in the simulation and the experimental prototype, the MOSFET output capacitance affects the behavior of the resonant converter.

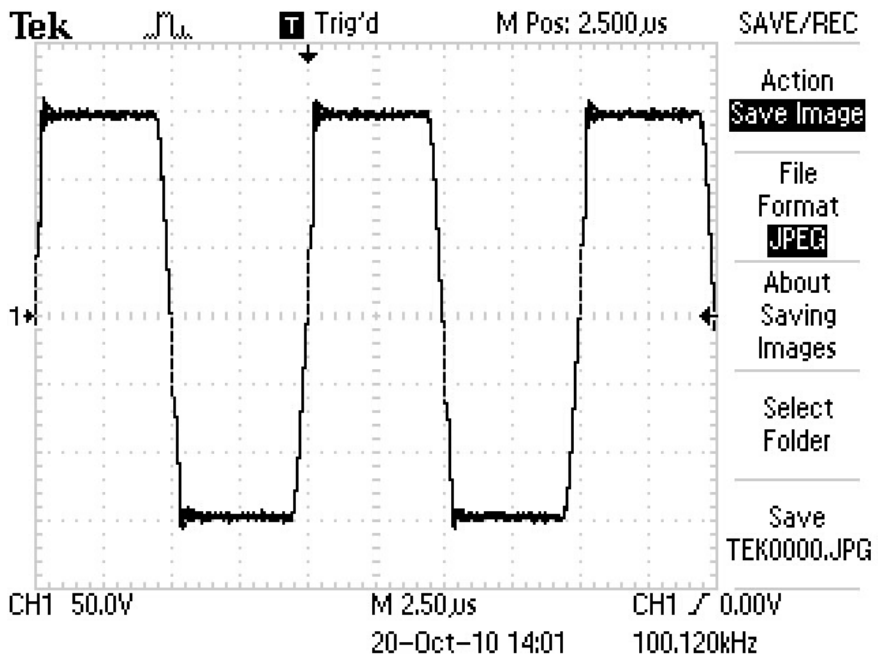

(a)

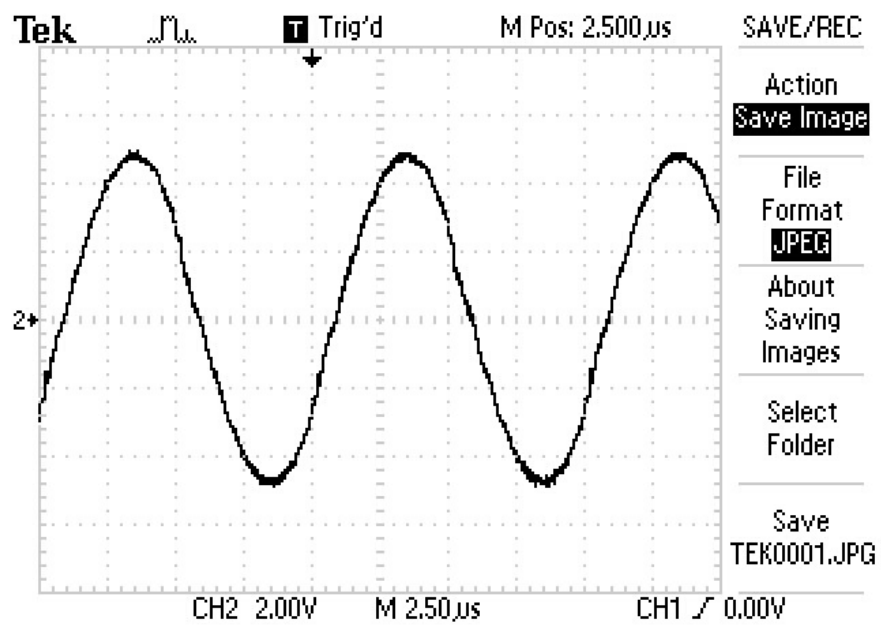

(b)

Fig. 7. Experimental results of LCLC resonant converter with capacitive output filter for full load condition. (a) Output voltage of full-bridge inverter (100V/Div). (b) Series inductance current (2A/Div).

\section{CONClusion}

In this paper, a new analysis is proposed by using the statespace approach which is able to precisely predict the behavior of a LCLC resonant converter with a capacitive output. Due to the specification of operation above the resonant frequency, an exact equation was obtained for the ZVS time. The accuracy of the state-space analysis is examined through a simulation and an experimental prototype.

\section{ACKNOWLEDGMENT}

This project was supported by the Malek-Ashtar University of Technology, Isfahan, Iran. 


\section{APPENDIX}

$$
\begin{gathered}
t_{2}=\frac{T_{s}}{2 \pi} \arctan \left(\frac{1}{16} \frac{1}{\pi^{5} f_{s}^{4} L_{p}^{2} C_{p} C_{s} \sin (\alpha)^{2}}\left(\begin{array}{c}
-4 L_{p} \pi^{2} f_{s}^{2} C_{s} \alpha \sin (2 \alpha)+8 L_{p}^{2} \pi^{5} f_{s}^{4} C_{s} C_{p} \sin (2 \alpha)-16 L_{p}^{2} \pi^{5} f_{s}^{4} C_{s} C_{p} \alpha+ \\
4 L_{p} \pi^{2} f_{s}^{2} C_{s} \alpha^{2}-4 L_{p} \pi^{2} f_{s}^{2} C_{s} \cos (\alpha)^{2}+4 L_{p} \pi^{2} f_{s}^{2} C_{s}-4 \pi^{3} C_{p} L_{p} f_{s}^{2} \sin (2 \alpha)+ \\
\alpha \sin (2 \alpha)+8 \pi^{3} C_{p} L_{p} f_{s}^{2} \alpha-\alpha^{2}-16 \pi^{6} C_{p}^{2} L_{p}^{2} f_{s}^{4}+\cos (\alpha)^{2}-1 \\
+16 L_{s} \pi^{5} f_{s}^{4} C_{s} C_{p} L_{p} \sin (2 \alpha)-4 L_{s} \pi^{2} f_{s}^{2} C_{s} \alpha \sin (2 \alpha)-32 L_{s} \pi^{5} f_{s}^{4} C_{s} C_{p} L_{p} \alpha+ \\
4 L_{s} \pi^{2} f_{s}^{2} C_{s} \alpha^{2}+64 L_{s} \pi^{8} f_{s}^{6} C_{s} C_{p}^{2} L_{p}^{2}-4 L_{s} \pi^{2} f_{s}^{2} C_{s} \cos (\alpha)^{2}+4 L_{s} \pi^{2} f_{s}^{2} C_{s}
\end{array}\right)\right) \\
\text { and } \alpha=\frac{\pi}{2}-2 \arctan \left(\begin{array}{l}
1+4 R_{L} f_{s} C_{p}-4 \sqrt{\frac{R_{L} f_{s} C_{p}}{\left(1+4 R_{L} f_{s} C_{p}\right)^{2}}}\left(1-4 R_{L} f_{s} C_{p}\right) \\
1-4 R_{L} f_{s} C_{p}
\end{array}\right)
\end{gathered}
$$

\section{REFERENCES}

[1] M. K. Kazimierczuk and D. Czarkowski, Resonant Power Converters, JohnWiley and Sons Inc., 1995.

[2] R. W. Erickson, Fundamentals Of Power Electronics, Kluwer Academic Publishers, 1997.

[3] I. Batarseh, "Resonant converter topologies with three and four energy storage elements," IEEE Trans. Power Electron., Vol. 9, No. 1, pp. 6473, Jan. 1994.

[4] R. L. Steigerwald, "A comparison of half-bridge resonant converter topologies," IEEE Trans. Power Electron., Vol. 3, No. 2, pp. 174-182, Apr. 1988.

[5] A. K. S. Bhat, "Fixed-frequency PWM series-parallel resonant converter," IEEE Trans. Ind. Appl., Vol. 28, No. 5, pp. 1002-1009, Sep./Oct. 1992.

[6] H. I. Sewell, M. P. Foster, C. M. Bingham, D. A. Stone, D. Hente, and D. Howe, "Analysis of voltage output LCC resonant converters, including boost mode operation," IEE Proceeding Electronics Power Application, Vol. 150, No. 6, pp. 673-679, Nov. 2003.

[7] J. A. Martin-Ramos, J. Diaz, A. M. Pernia, J. M. Lopera, and F. Nuno, "Dynamic and steady-state models for the PRC-LCC resonant topology with a capacitor as output filter," IEEE Trans. Ind. Electron., Vol. 54, No. 4, pp. 2262-2275, Aug. 2007.

[8] Y. A. Ang, C. M. Bingham, M. P. Foster, D. A. Stone, and D. Howe, "Design oriented analysis of fourth-order LCLC converters with capacitive output filter," IEE Proceeding Electronic Power Application, Vol. 152, No. 2, pp. 310-322, Mar. 2005.

[9] J. L. Sosa, M. Castilla, J. Miret, L. G. Vicuna, and J. Matas, "Modeling and performance analysis of the DC/DC series-parallel resonant converter operating with discrete self-sustained phase-shift modulation technique," IEEE Trans. Ind. Electron., Vol. 56, No. 3, pp. 697-705, Mar. 2009.

[10] M. Borage, K. V. Nagesh, M. S. Bhatia, and S. Tiwari, "Design of LCL-T resonant converter including the effect of transformer winding capacitance," IEEE Trans. Ind. Electron., Vol. 56, No. 5, pp. 1420-1427, May. 2009.

[11] E. H. Kim and B. H. Kwon, "Zero-voltage- and zero-current-switching full-bridge converter with secondary resonance," IEEE Trans. Ind. Electron., Vol. 57, No. 3, pp. 1017-1025, Mar. 2010.

[12] J. H. Cheng and A. F. Witulski, "Analytic solutions for LLCC parallel resonant converter simplify use of two-and three-element converters," IEEE Trans. Power Electron., Vol. 13, No. 2, pp. 235-243, Mar. 1998.

[13] P. K. Jain and M. C. Tanju, "A unity power factor resonant AC/DC converter for high-frequency space power distribution system," IEEE Trans. Power Electron., Vol. 12, No. 2, pp. 325-331, Mar. 1997.

[14] Z. Ye, P. K. Jain and P. C. Sen, "A two-stage resonant inverter with control of the phase angle and magnitude of the output voltage," IEEE Trans. Ind. Electron., Vol. 54, No. 5, pp. 2797-2812, Oct. 2007.

[15] W. G. Chen, Y. H. Rao, C. H. Shan, G. Fujita, and T. Yasutoshi, "The design and experiment of Ion Generator power supply for Vacuum Sputtering," in Proceeding IEEE PCC, pp. 931-935, 2007.

[16] C. Liu, F. Teng, C. Hu, and Z. Zhang, "LCLC resonant converter for multiple lamp operation ballast," in Proceeding IEEE APEC, pp. 12091213, 2003.
[17] A. Conesa, G. Velasco, H. Martinez, and M. Roman, "LCLC resonant converter as maximum power point tracker in PV systems," in Proceeding IEEE EPE, pp. 1-9, 2009.

[18] M. Borage, S. Tiwari, and S. Kotaiah, "Analysis and design of an LCLT resonant converter as a constant-current power supply," IEEE Trans. Ind. Electron., Vol. 52, No. 6, pp. 1547-1554, Dec. 2005.

[19] Y. Ang, C. M. Bingham, M. P. Foster, D. A. Stone, "Analysis and control of dual-output LCLC resonant converters, and the impact of leakage inductance," in Proceeding IEEE PEDS, pp. 145.150, 2007.

[20] J. A. Martin-Ramos, A. M. Pernia, J. Diaz, F. Nuno, and J. A. Martinez, "Power supply for a high-voltage application," IEEE Trans. Power Electron., Vol. 23, No. 4, pp. 1608-1619, Jul. 2008.

[21] J. Biela and J. W. Kolar, "Using transformer parasitics for resonant converters - a review of the calculation of the stray capacitance of transformers," IEEE Trans. Ind. Appl., Vol. 44, No. 1, pp. 223-233, Jan./Feb. 2008.

[22] C. Iannello, S. Luo, and I. Batarseh, "Full bridge ZCS PWM converter for high-voltage high-power applications," IEEE Trans. Aerosp. Electron. Syst., Vol. 38, No. 2, pp. 515-526, Apr. 2002.

[23] C. B. Viejo, M. A. P. Garcia, M. R. Secades, and J. U. Antolin, "A resonant high voltage converter with C-type output filter," in Proceeding IEEE IAS, pp. 2401-2407, 1995.

[24] J. A. Pomilio and C. J. B. "Pagan, resonant high-voltage source working at resonance for pulsed laser," in Proceeding IEEE PESC, pp. 16271632, 1996.

[25] V. Garcia, M. Rico, J. Sebastian, M. M. Hernando, and J. Uceda, "An optimized DC-to-DC converter topology for high-voltage pulse-load applications," in Proceeding IEEE PESC, pp. 1413-1421, 1994.

[26] Y.A. Ang, M. P. Foster, C. M. Bingham, D. A. Stone, H. I. Sewell, and D. Howe, "Analysis of 4th-order LCLC resonant power converters," IEE Proceeding.-Electronic Power Application, Vol. 151, No. 2, pp. 169-181, Mar. 2004.

[27] R. Beiranvand, B. Rashidian, M. Zolghadri, and M. Alavi, "Optimizing the normalized dead-time and maximum switching frequency of a wide adjustable range LLC resonant converter," IEEE Trans. Power Electron., Vol. 26, No 2. pp. 462-472, Mar. 2010.

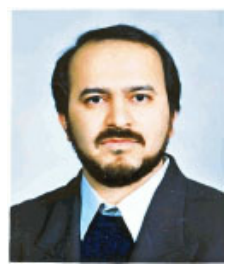

Mehrdad Jafarboland was born in Isfahan, Iran in 1964. He received his B.S. and M.S. in Electrical Engineering from the Science and Industrial University, Tehran, Iran, in 1979, and the Tarbiat Modares University, Tehran, Iran, in 1982, respectively. He received his Ph.D. in Electrical Engineering from the Science and Research unit of the Islamic Azad University Tehran, Iran, in 2002. After graduating, he became an Assistant Professor in the Department of Electrical Engineering, Malek-Ashtar University of Technology, Isfahan, Iran. He has been working in the Marine Research Center since 1987 and the Aerospace Research Center since 1995. His research interests include the control of large-scale systems, nonlinear systems control, electric machines, power electronics and the electric equipment of submarines and satellites. 